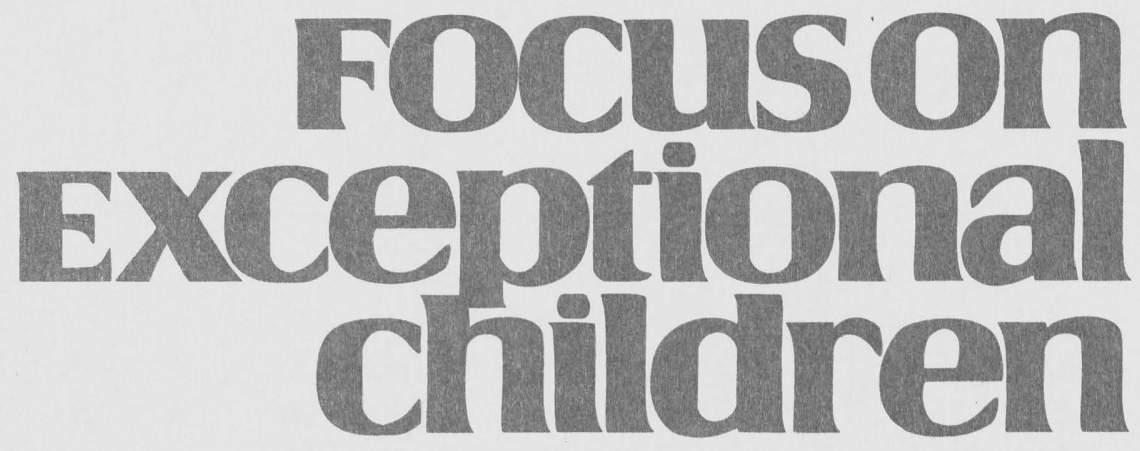

\title{
Current Practices with Young Children Who Have Disabilities: Placement, Assessment, and Instruction Issues
}

\author{
Mark Wolery, Margaret Gessler Werts, and Ariane Holcombe
}

In the relatively brief history of early childhood special education, various events have exerted substantial influence on the nature and focus of service provision: legislative events, the development of journals, the accumulation of research, and the description of developmentally appropriate practices by the National Association for the Education of Young Children (NAEYC). Legislative initiatives resulted in fiscal resources and policy shifts. For example, passage of PL 90-538 in 1968 started the Handicapped Children's Early Education Program (now called the Early Education Program for Children with Disabilities). This program funded numerous model demonstration projects, outreach endeavors, and research institutes that had consistent and enduring impacts on the field. Likewise, passage of PL 99-457 in 1986 and the subsequent amendments have increased the probability of making free appropriate public education a reality for preschoolers with disabilities.

Professional periodicals specifically devoted to early intervention and early childhood special education have appeared in the past 15 years. Examples are the Journal of Early Intervention (first published in 1979), Topics in Early Childhood Special Education (first published in 1981), and Infants and Young Children (first published in 1988). These journals, among others, offer authors in the field a forum for disseminating their findings and insights to readers whose primary interest is service provision for young children with disabilities.

In addition, the accumulation of research and experience in various areas of service delivery has caused substantial shifts in what is viewed as acceptable practice. Two salient examples of these shifts are the move toward family-centered/focused early education programs and the shift toward providing classroom-based services in integrated settings. From the 1960s through the early 1980s, families often were viewed as resources to conduct home-based interventions for children and as subjects of training provided by program personnel (Cartwright, 1981). Drawing on a family systems perspective (Foster, Berger, \& McLean, 1981), however, investigators began to study and report alternative approaches. These alternatives (e.g., Bailey et al., 1986; Dunst, 1985; Dunst, Trivette, \& Deal, 1988) have been shown to be attractive and effective; thus, they currently are viewed as acceptable practice (Dunst, Trivette, Starnes, Hamby, \& Gordon, 1993).

Similarly, the first classroom-based services for young children with disabilities often were segregated programs for children with heterogenous disabilities. In the early 1970s,

Mark Wolery and Margaret Gessler Werts are with the Child and Family Studies Program, Department of Psychiatry, Allegheny-Singer Research Institute, Pittsburgh. Ariane Holcombe is a doctoral student in the Department of Special Education, Vanderbilt University. 
however, Bricker and Bricker (1973) demonstrated the feasibility of educating young children with and without disabilities in the same program. Over time, the rationale for these programs emerged (Bricker, 1978), model programs were developed (e.g., Rule et al., 1987; Templeman, Fredericks, \& Udell, 1989), and research was conducted and summarized (Guralnick, 1978; Odom \& McEvoy, 1988; Peck \& Cooke, 1983). Currently, the value of integrated programs is well recognized, and these arrangements no longer are considered novel or innovative; rather, they are perceived as acceptable practice (Peck, Odom, \& Bricker, 1993).

These forces were the result of efforts by individuals whose primary identity was within the field of early intervention/early childhood special education - both as professionals and as family members of children with disabilities. A recent force that is influencing early childhood special education practice (especially classroom-based practices) comes from outside the field of early childhood special educationspecifically, the guidelines on developmentally appropriate practice (DAP) (Bredekamp, 1987) published by NAEYC.

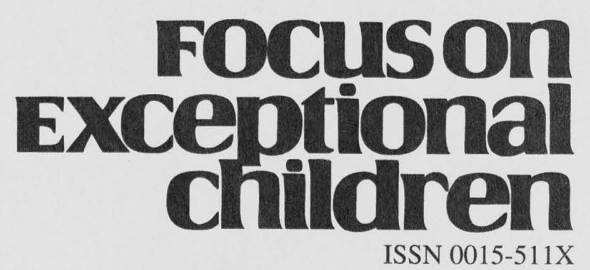

FOCUS ON EXCEPTIONAL CHILDREN (USPS 203-360) is published monthly except June, July, and August as a service to teachers, special educators, curriculum specialists, administrators, and those concerned with the special education of exceptional children. This publication is annotated and indexed by the ERIC Clearinghouse on Handicapped and Gifted Children for publication in the monthly Current Index to Journals in Education (CIJE) and the quarterly index, Exceptional Children Education Resources (ECER). It is also available in microfilm from Xerox University Microfilms, Ann Arbor, MI. Subscription rates: Individual, \$30 per year; institutions, \$40 per year. Copyright (C) 1994, Love Publishing Company. All rights reserved. Reproduction in whole or part without written permission is prohibited. Printed in the United States of America. Second class postage is paid at Denver, Colorado. POSTMASTER: Send address changes to:

Love Publishing Company

Executive and Editorial Office

1777 South Bellaire Street

Denver, Colorado 80222

Telephone (303) 757-2579

Edward L. Meyen

University of Kansas

Richard J. Whelan

University of Kansas Medical Center
Glenn A. Vergason Georgia State University
Stanley F. Love
Publisher
The DAP guidelines were developed to address issues within the field of early education (e.g., widely discrepant practices across programs, downward extension of the elementary curriculum to kindergarten and preschool programs) and to assist programs in meeting the accreditation process by NAEYC (Bredekamp, 1993). These guidelines, however, have had a substantial impact on what is viewed as acceptable early childhood special education practice (Carta, Schwartz, Atwater, \& McConnell, 1991; Carta, Atwater, Schwartz, \& McConnell, 1993; J. Johnson \& K. Johnson, 1992; K. Johnson \& J. Johnson, 1993; Norris, 1991).

A description of the DAP guidelines is beyond the scope of this article, and readily available sources describe the guidelines in detail (Bredekamp, 1987, 1991; Bredekamp \& Rosegrant, 1992, in press; Kostelnik, 1992; NAEYC-NAECS/ SDE, 1991). For discussions of the relationship of the DAP guidelines to early childhood special education practice, see Bredekamp (1993); Cavallaro, Haney, and Cabello (1993); McLean and Odom (1993); Novick (in press); Wolery and Bredekamp (in press); and Wolery, Strain, and Bailey (1992).

The purpose of this article is twofold: (a) to explore the effects of the integration movement on the placement of preschoolers with disabilities, and (b) to describe the effects of integration and DAP on assessment and instructional practices. Placement issues are discussed first, followed by descriptions of assessment and instructional practices. Emphasis is given to services for preschoolers with disabilities (children 3 through 5 years of age) rather than for infants and toddlers.

\section{PLACEMENT ISSUES}

Placement can be defined as the site of primary service delivery. Several rationales can be proposed for placing young children with disabilities in integrated settings, those that include children with typical development (Bricker, 1978). The arguments include the philosophic perspectives that integration eliminates the stigmatizing effects of segregated programs; legal precedents (e.g., least restrictive placement provisions); and empirical arguments that integrated programs are as effective as segregated programs. In fact, the data seem to indicate that developmental progress for children with disabilities is at least as good in integrated as in segregated programs and that integrated programs hold some advantage in terms of promoting social skills (Buysse \& Bailey, 1993).

\section{Background}

Placement for elementary-school-aged children with disabilities is often in educational contexts such as public school 
programs, especially since implementation of PL 94-142. Nevertheless, the primary site of services for preschoolers with disabilities historically has been quite diverse, including children's homes, specialized preschools (private and public), child care programs, clinics, and hospitals (Bailey \& Wolery, 1992). Several historic factors may account for this diversity.

1. Most local education agencies did not provide programs for preschool children regardless of whether the children had or did not have disabilities. Under PL 94-142, states were allowed to provide services for children with disabilities beginning with age 3, but most did not (Garwood \& Sheehan, 1989). Thus, free appropriate public education generally was not available to preschoolers (children ages 3 through 5) with disabilities.

2. The model-demonstration program of the Handicapped Children's Early Education Program provided funds for development of an array of service arrangements and options. This resource resulted in creative alternatives to public school, classroom-based services.

3. The diverse needs of young children with disabilities, their age, and the priorities of their families suggest that a single placement option (e.g., public school classrooms) was not universally appropriate.

4. Because no public agency was required to provide services, a variety of different types of agencies developed services in response to community needs. These agencies had differing levels of resources (personnel and fiscal), differing missions, and differing philosophic and conceptual approaches to service provision. As a result, an array of placements existed across communities. Families of preschoolers with disabilities, however, often had relatively few placement options. In some communities, no programs existed; and in other communities a sole service provider existed and used a single placement (e.g., home-based) regardless of the appropriateness of the placement for individual children. Thus, families' choice often focused on accepting/not accepting services rather than choosing services from an array of potential placements.

A notable exception to this piecemeal service delivery was the national Head Start program. In 1974, PL 93-644 amended the Head Start legislation and required that $10 \%$ of the children enrolled in each state be young children with disabilities (Garwood \& Sheehan, 1989). Head Start consistently met this mandated percentage, and the largest percentage of enrolled children with disabilities consisted of those who had speech-language impairments.

The 1986 amendments (PL 99-457) to the Education of the Handicapped Act (now called the Individuals with Disabilities
Education Act, IDEA) changed Part B of the Act to require free appropriate public education for preschoolers with disabilities. As a result, they now are entitled to the provisions previously guaranteed to older children with disabilities (Turnbull, 1990). In terms of placement, two provisions are important: (a) shared decision making between the family and other team members in selecting a placement, and (b) placement in the least restrictive appropriate environment.

The least restrictive placement provision, as applied to older children, traditionally was conceptualized as a continuum of possible settings. For example, students within a given school district may be enrolled in a segregated (special) school with minimal contact with typically developing students, in a segregated class in a cluster or neighborhood school with varying levels of regular contact with typical students, in a resource room (part-time special placement) and concomitant enrollment in general education classes (regular and consistent contact with typical peers), and in a general education classroom with consultative special services (extensive contact with typical peers). Those advocating full inclusion have duly criticized this conceptualization (Taylor, 1988), because few children move through the continuum to less restrictive placements. Further, it may pose problems for preschoolers with disabilities because, with the exception of kindergarten, many schools do not have services for preschoolers with typical development. Thus, the questions become: To what extent are preschoolers with disabilities enrolled in programs for typically developing children? What barriers exist to such enrollment?

\section{Enrollment in Integrated Settings}

Although the percentage of preschoolers with disabilities who receive services in integrated settings is not known precisely, some information bears on this issue. In its latest report to Congress on the implementation of IDEA, the U. S. Department of Education (1993) stated that $84 \%$ of the 3through 5-year-old children with disabilities received their services in regular school buildings; $13 \%$ received services in special schools; and the remainder (3\%) received services in their homes, residential facilities, or hospitals. As indicated in the report, however, receiving services in a regular school building is not equivalent to being placed in an integrated program. The lack of 3-and 4-year-old typically developing children in many schools means that 3- and 4-year-old children with disabilities might not have regular contact with their agemates in their intervention settings.

In addition to this information, surveys of personnel in preschool programs designed for typically developing children indicate that many of these programs enroll children with disabilities. Wolery, Holcombe, et al. (1993) surveyed a ran- 
domly selected national sample from four types of preschool programs: Head Start programs, public school prekindergarten programs, public school kindergartens, and community programs (private for- and not-for-profit programs, military programs, church/synagogue programs, corporate child care, etc.). Respondents were asked to identify the number of children who were enrolled with diagnosed disabilities by age and diagnosis and to indicate whether they had enrolled children with disabilities in the four previous years.

The respondents indicated that $94 \%$ of the Head Start programs, $73 \%$ of the public school prekindergarten programs, $81.5 \%$ of the public school kindergarten programs, and $59.2 \%$ of the community programs enrolled at least one child with a diagnosed disability during the 1989-90 school year (Wolery, Holcombe, et al., 1993). Interestingly, the percentage of programs for each group that reported enrolling children with disabilities increased over each of the four previous years, with one exception (the percentage of Head Start programs enrolling children with disabilities reportedly was identical in 1986-87 and 1987-88). For the public school and community programs, the largest increases occurred from the 1988-89 school year to the 1989-90 school year. More recent data (1992-93 school year) are available for public school kindergarten programs. Wolery, Werts, Snyder, and Caldwell (1993) surveyed randomly selected kindergarten teachers from throughout the nation; $73 \%$ reported enrolling at least one child with a diagnosed disability.

As with the Head Start data, both of these surveys indicate that the diagnosis reportedly enrolled in the largest percentage of programs was speech-language impairments - $57.5 \%$ of the programs in the Wolery, Holcombe, et al. (1993) study, and $64 \%$ of the kindergartens in the Wolery, Werts, et al. (1993) study. Although the U. S. Department of Education (1993) did not report the number of 3- through 5-year-old children by disability type, it reported the number of 6-yearold children by each disability. In 1991-92 (last reporting year), $71.1 \%$ of the 6 -year-old children with disabilities were reported to have speech impairments.

In both surveys (Wolery, Holcombe, et al., 1993; Wolery, Werts, et al., 1993), respondents reported enrolling children with sensory impairments, behavior disorders, moderate to severe mental retardation, and physical disabilities. For example, Wolery, Holcombe, et al. (1993) found that $8.5 \%$ of the programs reported enrolling children with moderate to severe mental retardation, and Wolery, Werts, et al. (1993) found that $4.5 \%$ of the kindergartens reported enrolling such children. Together, these data indicate that many programs for typically developing children report enrolling children with disabilities and that children with a variety of different disabilities are apparently enrolled. These data, however, were based on teachers' reports of children's diagnoses. Information does not exist from these studies about the criteria used to make the diagnoses nor about the reliability with which the diagnoses were assigned. Similarly, little information exists about the quality of these placements for the children with disabilities who were enrolled in the classrooms.

Future research should address the limitations of the studies described-particularly, as it relates to the actual amount of integration that is occurring. For example, more information is needed about the placements of 3-and 4-year-old children with disabilities and about the effects of different disabilities on placement decisions.

\section{Barriers to Placement in Integrated Settings}

Despite the data reported above, segregated programs continue to exist. Of the preschoolers with disabilities, at least $13 \%$ (undoubtedly a substantial underestimation) are served in segregated schools (U. S. Department of Education, 1993). Several levels of barriers exist to widespread, high quality integration of preschoolers with disabilities. Odom and McEvoy (1990) proposed five barriers to preschool integration: (a) philosophic and theoretical differences between general and special early childhood educators, (b) inadequate preparation of general and special early educators concerning integration, (c) negative attitudes about integration, (d) lack of systems to monitor non-public school placements, and (e) provision of related services in integrated contexts. These are discussed below.

First, although some philosophic differences clearly exist between general and special early educators (cf. Carta et al., 1993; Johnson \& Johnson, 1993), differences also exist within both fields (Wolery \& Bredekamp, in press). These differences are most pronounced in terms of instructional practices (discussed later in the article). Nevertheless, substantial agreement exists on many relevant issues, which provides a foundation for convergence between the two fields (see Topics in Early Childhood Special Education, 13(3), for a special issue on this topic).

Second, the level and type of personnel preparation is clearly a potential barrier to high-quality integrated services and potentially to integrated placements (Burton, Hains, Hanline, McLean, \& McCormick, 1992). Integration requires shifts in the roles and role expectations of general and special educators alike (Kontos \& File, 1993; Buysse \& Wesley, in press). In fact, personnel standards-policies focusing on who can provide special education and related services - are a major policy barrier (U. S. Department of Education, 1993). 
In a national survey of faculty members who prepare general early childhood educators, lack of adequate training and consultation was listed more frequently than any other barrier to preschool mainstreaming (Wolery, Huffman, Holcombe, et al., in press), and it was the second most frequently listed barrier (after high child-to-staff ratios) by general early educators themselves (Wolery, Huffman, Brookfield, et al., in press). Fortunately, a number of models of staff development exist (Kontos \& File, 1993). Thus, this issue can be dealt with by resolving policy issues related to personnel standards at the state and local levels and ensuring that staff development is provided.

Nonetheless, several issues related to personnel preparation require additional investigation. These include the effects of providing merged preservice preparation in general and special early education (Burton et al., 1992; Stayton \& Miller, 1993), although many of the individuals employed in preschool programs do not have formal training in either discipline (Wolery, Martin, Schroeder, et al., in press). Also, the effects of various forms of consultation require further study (Pugach \& Johnson, 1990). In addition to preservice and staff development activities, research attention must focus on the contextual factors (e.g., high child-to-staff ratios) that interfere with and promote teachers' use of effective practices (Kontos \& File, 1993).

Third, Odom and McEvoy (1990) say that negative attitudes about integration is a barrier to preschool mainstreaming. Attitudes about integration occur on many dimensions, such as attitudes of parents with and without children who have disabilities about integration, attitudes of teachers and administrators about integration, attitudes of teachers and administrators about parents of children with disabilities, and attitudes of children with typical development about their peers with disabilities (Stoneman, 1993). Generally, parents of children with and without disabilities are disposed positively toward integration, although studies show variable results (Bailey \& Winton, 1987; Peck, Carlson, \& Helmstetter, 1992). In a national survey, about $28 \%$ of faculty members who prepare general early educators listed objections of parents, teachers, and administrators (i.e., negative attitudes) as a barrier to mainstreaming (Wolery, Huffman, Holcombe, et al., in press), but less than $10 \%$ of the general early childhood educators in a similar national survey listed these objections as a barrier (Wolery, Huffman, Brookfield, et al., in press). Teachers and administrators, however, may have less positive attitudes toward parents of children with disabilities than toward parents of typically developing children (Stoneman, 1993).

Children's attitudes toward their peers with disabilities is fraught with methodological problems, but, in general, young children note those who are different from themselves and prefer children similar to themselves (Stoneman, 1993). Also, children without disabilities spend more time playing with peers without disabilities than with peers who have disabilities (Guralnick, 1981). Parents and other adults seem to influence the formation of attitudes in children.

Research is needed on the effects of various attitudes of relevant individuals about integration. Clearly, further description of the attitudes of teachers and administrators toward parents of children with disabilities is an important area for study. Likewise, the effects of integration on children's attitudes toward their peers with disabilities and the extent to which attitudes and opportunities for interaction influence one another are pertinent topics for additional investigation.

Fourth, the lack of state monitoring systems and broader policy issues are potential barriers to integration. Smith and Rose (1993) identified six categories of policy barriers:

Program Standards: restrictive policies related to program or personnel characteristics; supervision of special eduction implementation; and "approval" policies for non-public school placements.

Personnel Standards: restrictive policies related to personnel characteristics.

Fiscal Policies: policies primarily governing the use of funds (i.e., limitation on use of certain funding streams for certain personnel or students, or limitations on the use of funds in or for non-public school settings including separation of church and state prohibitions). Also this category includes how funds are generated (i.e., child count or per "unit"); amounts available (re: rate-setting, amounts needed for mainstreaming, etc.); and how much time and service for which to contract.

Eligibility Policies: refers to differences in criteria used to allow children to participate in services. The policy barriers are related to differences in the criteria between special education and mainstream entities [Head Start, child care, "at-risk," Chapter I (ESEA), kindergarten, etc.].

Transportation Policies: policies governing availability, schedules, and prohibitions on non-public school or district use.

Coordination Policies: usually the lack of policies related to coordination of procedures, programs, and services critical to planning and delivery of special education and related services in mainstream settings.

They also proposed a process for assisting local personnel in identifying and addressing policy barriers. The general categories of policy barriers were generated from a survey and interviews with relevant individuals. Future research should address the extent to which policy issues such as these are actually interfering with children being placed in integrated settings. Also, additional research should identify strategies for removing these barriers and the effects of removing those barriers on actual practice. For example, if personnel standards allow individuals with diverse training to provide spe- 
cial education services, the issue becomes whether the quality of services is diminished.

The fifth and final barrier proposed by Odom and McEvoy (1990) is the provision of related services. Many preschoolers with disabilities require services from a number of disciplines (e.g., speech-language pathology, physical therapy, occupational therapy, social work) (Bruder, in press). The literature does not indicate whether they are receiving these services in integrated settings. From national survey data, a couple of issues are clear (Wolery, Venn, Holcombe, et al., in press):

1. Most preschool programs designed for children with typical development do not employ related service personnel, even on a part-time consultant basis, despite the fact that children with disabilities are enrolled.

2. These programs enroll children with specific disabilities without employing, even on a part-time consultant basis, members of disciplines related to that disability.

For example, nearly half $(44.5 \%)$ of the preschool programs that enrolled at least one child with speech-language disorders do not employ a speech-language pathologist (Wolery, Venn, Schroeder, et al., in press). These data are limited: The children's related service needs were not identified, and the services may be provided by individuals who are not employed by the programs.

More research is needed to determine whether young children's related service needs are being addressed adequately in integrated placements. Also, issues related to how that therapy is implemented (e.g., within classrooms or in pull-out situations) deserve study (McWilliam \& Bailey, in press). Finally, information is needed in terms of the quality of communication among related service personnel, educators, and family members, and, of course, on strategies for fostering collaboration.

In sum, the site of services for preschoolers with disabilities traditionally has been more diverse than for their school-age peers with disabilities. Although a large percentage of the preschool programs designed for typically developing children enroll children with disabilities, the percentage of preschool children with disabilities enrolled in integrated placements is not known. Substantial research is needed to address the barriers to integrated placement. Placement does not equate to services, however. The nature and extent of services within programs is likely to have a greater influence on outcomes than the mere fact of placement (Fewell \& Oelwein, 1990).

\section{ASSESSMENT PRACTICES}

Several trends emerged in the assessment of preschoolers with disabilities over the past decade. These included more reliance on judgment-based assessment (Fleischer, Belgredan, Bagnato, \& Ogonosky, 1990; Neisworth \& Fewell, 1990); less reliance on standardized tests and testing procedures (Bailey \& Wolery, 1989; Neisworth \& Bagnato, 1992); more recognition of the value of assessing children's behavior in context using direct and ongoing observation, including eco-behavioral assessment (Barnett, Macmann, \& Carey, 1992; Benner, 1992; Carta, Sainato, \& Greenwood, 1988); and increased recognition of the value of using different assessment practices for different assessment purposes such as screening, diagnosis, instructional program planning, and program evaluation (Wolery, Strain, \& Bailey, 1992).

These trends parallel the DAP guidelines and are quite consistent with NAEYC's position concerning assessment of typically developing children (Bredekamp, 1987; NAEYC \& NAECS/SDE, 1991). For example, the NAEYC \& NAECS/ SDE (1991) position statement on curriculum and assessment describes three purposes of assessment:

1. Assessment for planning instruction.

2. Assessment for screening and diagnosis.

3. Assessment for program evaluation.

The guidelines include using direct observation in real contexts, putting stock in teacher judgment, and minimizing the use of standardized tests. Thus, in terms of assessment, the DAP guidelines are consistent with accepted practices in early childhood special education (Bagnato, Neisworth, \& Munson, 1989; Bailey \& Wolery, 1989; Benner, 1992).

Despite the consistency in the general views about assessment of young children between general and special early educators, four differences are noteworthy and deserve future research attention. First, young children with disabilities usually are involved in more assessment activities than are young children without disabilities. This is necessary for diagnosis, for IEP development, and for monitoring the effects of instructional activities. Future research should determine whether general early educators who follow the DAP guidelines recognize the need for this additional assessment; what training, if any, is necessary for helping them implement appropriate assessment activities (e.g., ongoing systematic data collection); and the extent to which such activities interfere with classroom activities.

Second, families of children with disabilities are likely to be more involved in the assessment activities than are families of children without disabilities. In the DAP assessment guidelines (NAEYC \& NAECS/SDE, 1991) emphasis is placed primarily on communicating the findings of assessments to families. In early childhood special education the emphasis is on planning the assessment together, collecting some assessment data with the family, relying extensively on 
families' views of instructional priorities and child behavior, and developing the instructional plan (the IEP) with the family. Future research should address the effects of this role shift on the behaviors of general early education teachers. For example, does being involved with families of children with disabilities during assessment activities result in more "family-friendly" assessment activities being used with families of typically developing children?

Third, representatives from several different disciplines are likely to be more involved in the assessment of children with disabilities than in the assessment of children without disabilities (Bruder, in press). With the exception of screening activities, most typically developing children have little sustained contact with professionals from related service disciplines. The involvement of these professionals in the general early education classroom constitutes a meaningful shift in the classroom ecology. General early educators must acquire the terminology used in various disciplines and must employ skills in working with other adults. Future research should address the extent to which the involvement of related service providers in the early education classroom changes the practices of those settings for the staff and for the children with typical development. Also, the way in which related services are provided (e.g., pull-out or integrated services) deserves additional attention.

Fourth, for instructional program planning assessments, a formal written plan (the IEP) is required for children with disabilities, but IEPs are not required for typically developing children. We do not know yet how general early childhood educators will use the IEP and whether they will view it as a static or a dynamic document. Future research should give attention to these issues. Development of an IEP, of course, requires joint decision making by a team, including family members, related service professionals, and educators. Thus, decisions about what and how to teach, which previously were the purview of the general educator, become joint decisions for children with disabilities. Research should identify the effects of this role change on general early educators' practices for typically developing children. Understanding the effects of this role shift is a priority for future research.

One issue that both general and special early educators face that is not totally resolved deals with the assessment of preschoolers whose families are culturally and linguistically different from the majority culture. For instructional program planning, the most reasonable approaches involve using direct observation in natural contexts (Barnett et al., 1992) and employing other adults as cultural and language mediators (Barrera, in press). These two approaches provide information on children's functional capabilities and information about families' perspectives and expectations. Future re- search should address the extent to which these practices actually result in instructional programs and practices that a range of families from different cultural and ethnic groups view as acceptable.

\section{INSTRUCTIONAL ISSUES}

Including children with disabilities in general early education classrooms that follow the DAP guidelines raises a number of questions. Most of these can be subsumed under the broad question: To what extent are the DAP guidelines appropriate for young children with disabilities? Several analyses of this issue have been set forth (Carta, Atwater, et al., 1993; Carta, Schwartz, et al., 1991; McLean \& Odom, 1993; Wolery, Strain, \& Bailey, 1992). From these reviews, the general conclusion is that preschool programs operating under the DAP guidelines are appropriate contexts for implementing the early education of young children with disabilities. Nevertheless, adaptations and extensions of the guidelines are likely needed for children with disabilities.

The question then becomes: Under what conditions and for which children are specific adaptations required? (Wolery \& Bredekamp, in press). Reports of various adaptations are beginning to appear in the literature (e.g., Fox \& Hanline, 1993; Venn, Wolery, Werts, et al., 1993). The reports, however, tend to point out the effects of specific adaptations rather than to analyze the conditions under which specific adaptations are required.

The DAP guidelines are based heavily on a constructivist perspective of child development and learning and, in part, on a social-constructivist perspective (NAEYC \& NAECS/SDE, 1991). As a result, child-initiated and child-directed learning is valued and promoted. Within this perspective important teaching functions are to provide interesting environments and materials, to arrange those environments and activities to promote children's engagement, and to support children's participation in those activities (Bredekamp, 1987). The importance and salience of these functions have resulted in a devaluation by some authors and practitioners of other teaching functions (particularly, teacher-guided practices). Recently, however, Bredekamp (1993) and Kostelnik (1992) have reasserted the value of the teacher's role in guiding learning, particularly in terms of responsive guiding.

Although a balance should be maintained between childand teacher-initiated activities, the value of teacher-guided learning is especially important for young children with disabilities. Substantial research documents the positive benefits of those approaches with children who have disabilities (Bailey \& Wolery, 1992; Odom, McConnell, \& McEvoy, 1992; Kaiser, Yoder, \& Keetz, 1992; Wolery, Ault, \& Doyle, 1992). 
Devising plans for children with disabilities who are included in classrooms following the DAP guidelines requires a subtle shift in program development. Rather than designing the classroom program based on children's identified needs (i.e., instructional objectives) as was done in segregated classrooms, emphasis is placed on adapting existing classroom activities and routines so that the child with disabilities will acquire important skills. In devising adaptations, a couple of themes have emerged:

1. Opportunities for children with disabilities to learn and practice new skills should be dispersed throughout the day during naturally occurring routines and activities (Bricker \& Cripe, 1992).

2. Instruction to promote children's acquisition and use of important skills should be embedded in ongoing activities and routines (Wolery, 1989).

These two themes are referred to as activity-based instruction (Bricker \& Cripe, 1992; Novick, in press).

Implementation of these themes follows a sequence discribed by Bailey and Wolery (1992). First, instructional objectives are identified through a careful assessment of children's abilities and needs conducted by the team including family members. An assessment also is done of children's daily schedules and routines, outside of as well as within the classroom environment. Based on this information, multiple opportunities throughout the day are identified for children to practice and learn the behaviors from each objective. In identifying the opportunities, consideration should be given to the roles and demands placed on teachers during various activities (Fleming, Wolery, Weinzierl, Venn, \& Schroeder, 1991). Ideally, the adaptations will be consistent with teachers' existing behaviors in various activities. This consideration also involves an analysis of the structure of activities (e.g., number of children present, the activity's purpose, the rules guiding children's behavior). Forms for conducting these analyses have been developed (Venn \& Wolery, 1991).

After analyzing the assessment data for the child and of the environment, a schedule (called an activity-by-skill matrix) is developed. This schedule specifies the times each objective will be addressed and the objectives that will be addressed for each activity and routine. Instructional materials and strategies are identified and selected. The plan then is implemented, accompanied by ongoing monitoring and assessment of the effects of the plan.

A number of guidelines have been developed for adapting existing classroom activities. Some of these are listed in the box at the end of this article, including brief examples and sample references. Although existing activities can be adapted successfully in most cases, teams also should reserve the op- tion of designing special and new activities to promote children's acquisition of skills that are not easily taught through adaptation of existing activities (Wolery \& Wilbers, in press).

Although the process of the activities-based approach is logical and practical and the guidelines for adapting activities have an emerging empirical foundation, the enrollment of children with disabilities in classrooms following the DAP guidelines requires further study. The DAP guidelines emphasize children's engagement with materials and in various activities. Clearly, promoting children's engagement also is a major priority of early childhood special educators (Bailey \& McWilliam, 1990; McWilliam, 1991). While engagement may be necessary for experiential learning to occur, it may not ensure (i.e., be sufficient) that such learning will occur. The tension lies in whether teachers should focus on promoting children's engagement in particular activities or whether they should focus on promoting engagement and on facilitating acquisition or use of a priori defined behaviors in those activities. In part, this deals with the type of engagement that is promoted (cf. McWilliam \& Bailey, 1992), but it also deals with the extent to which teachers use instructional strategies to promote defined behaviors.

Another area of future research deals with the types of skills that are promoted. Among others, the DAP guidelines are designed to help children:

- become curious about their world.

- be creative.

- engage in imaginative and pretend play.

- display personal initiative and responsibility.

- develop self-control and a sense of group membership.

- learn problem-solving skills.

- appreciate the fine arts.

Although these are desirable outcomes of early education for children with disabilities, relatively little is known about how to define and promote these skills for preschoolers with disabilities. Studies devoted to developing operational descriptions of these skills and building curricula to teach them are a clear priority.

Finally, a substantial amount of research is needed regarding implementation of the adaptations (described in the box) in early education classrooms, following the DAP guidelines. Some of this research should address when specific adaptations should be used. Other research should focus on the training necessary for helping general early educators implement the adaptations. Still other research should explore the consultant role of early childhood special educators and related service personnel. Finally, this research should be directed at the combined effects of implementing many of the adaptations simultaneously within classrooms. 


\section{CONCLUSION}

Services for preschoolers with disabilities have undergone a considerable amount of development and refinement in the past 25 years. The influences of the integration movement and developmentally appropriate practice (DAP) guidelines on current practice were discussed in this article. Although the precise extent and nature of preschool mainstreaming are not known, the data indicate that many preschool programs designed for typically developing children enroll youngsters with disabilities. The DAP guidelines related to assessment are quite consistent with recommended practices in early childhood special education, although some differences exist. In terms of instruction, a growing body of literature supports the conclusion that programs following the DAP guidelines can be adapted to promote positive benefits for young children with disabilities.

\section{REFERENCES}

Azrin, N. H., \& Armstrong, P. M. (1973). The "mini-meal": A method for teaching eating skills to the profoundly retarded. Mental Retardation, 11, 9-13.

Bagnato, S. J., Neisworth, J. T., \& Munson, S. M. (1989). Linking developmental assessment and early intervention: Curriculum-based prescriptions (2nd ed.). Rockville, MD: Aspen.

Bailey, D. B., \& McWilliam, R. A. (1990). Normalizing early intervention. Topics in Early Childhood Special Education, 10(2), 33-47.

Bailey, D. B., Simeonsson, R. J., Winton, P. J., Huntington, G. S., Comfort, M., Isbell, P., O’Donnell, K. J., \& Helm, J. M. (1986). Family-focused intervention: A functional model for planning, implementing, and evaluating individualized family services in early intervention. Journal of the Division for Early Childhood, 10, 156-171.

Bailey, D. B., \& Winton, P. J. (1987). Stability and change in parents' expectations about mainstreaming. Topics in Early Childhood Special Education, 7(1), 73-88.

Bailey, D. B., \& Wolery, M. (Eds.) (1989). Assessing infants and preschoolers with handicaps. Columbus, $\mathrm{OH}$ : Charles Merrill.

Bailey, D. B., \& Wolery, M. (1992). Teaching infants and preschoolers with disabilities (2nd ed.). Columbus, $\mathrm{OH}$ : Merrill.

Barnett, D. W., Macmann, G. M., \& Carey, K. T. (1992). Early intervention and the assessment of developmental skills: Challenges and directions. Topics in Early Childhood Special Education, 12(1), 21-43.

Barrera, I. (in press). Individualized instruction for all children: The challenge of cultural/linguistic diversity and young children with special needs. Topics in Early Childhood Special Education.

Benner, S. M. (1992). Assessing young children with special needs: An ecological perspective. White Plains, NY: Longman.

Bredekamp, S. (1987). Developmentally appropriate practice in early childhood programs serving children from birth through age 8 (rev. ed.). Washington, DC: NAEYC.

Bredekamp, S. (1991). Redeveloping early childhood education: A response to Kessler. Early Childhood Research Quarterly, 6, 199-209.

Bredekamp, S. (1993). The relationship between early childhood education and early childhood special education: Healthy marriage or family feud? Topics in Early Childhood Special Education, 13, 258-273.
Bredekamp. S., \& Rosegrant, T. (1992). Reaching potentials: Appropriate curriculum and assessment for young children (Vol. 1). Washington, DC: National Association for the Education of Young Children.

Bredekamp. S., \& Rosegrant, T. (in press). Reaching potentials: Appropriate curriculum and assessment for young children (Vol. 2). Washington, DC: National Association for the Education of Young Children.

Bricker, D. (1978). A rationale for the integration of handicapped and nonhandicapped preschool children. In M. Guralnick (Ed.), Early intervention and the integration of handicapped and nonhandicapped children (pp. 3-16). Baltimore: University Park Press.

Bricker, D., \& Bricker, W. A. (1973). Infant, toddler, and preschool research and intervention project report: Year III IMRID Behavioral Science Monograph No. 23. Nashville, TN: Institute on Mental Retardation \& Intellectual Development, George Peabody College.

Bricker, D., \& Cripe, J. J. W. (1992). An activity-based approach to early intervention. Baltimore: Paul H. Brookes.

Bruder, M. B. (in press). Working with members of other disciplines. In M. Wolery \& J. S. Wilbers (Eds.), Including children with special needs in preschool programs: Research and implications for practice. Washington, DC: NAEYC.

Burton, C. B., Hains, A. H., Hanline, M. F., McLean, M., \& McCormick, K. (1992). Early childhood intervention and education: The urgency of professional unification. Topics in Early Childhood Special Education, 11(4), 53-69.

Buysse, V., \& Bailey, D. B. (1993). Behavioral and developmental outcomes in young children with disabilities in integrated and segregated settings: A review of comparative studies. Journal of Special Education, 26, $434-461$

Buysse, V., \& Wesley, P. W. (in press). The identity crisis in early childhood special education: A call for professional role clarification. Topics in Early Childhood Special Education.

Carta, J. J., Atwater, J. B., Schwartz, I. S., \& McConnell, S. R. (1993). Developmentally appropriate practices and early childhood special education: A reaction to Johnson and McChesney Johnson. Topics in Early Childhood Special Education, 13, 243-254.

Carta, J. J., Sainato, D. M., \& Greenwood, C. R. (1988). Advances in the ecological assessment of classroom instruction for young children with handicaps. In S. L. Odom \& M. B. Karnes (Eds.), Early intervention for infants and young children with handicaps: An empirical base (pp. 217-239). Baltimore: Paul H. Brookes.

Carta, J. J., Schwartz, I. S., Atwater, J. B., \& McConnell, S. R. (1991). Developmentally appropriate practice: Appraising its usefulness for young children with disabilities. Topics in Early Childhood Special Education, 11(1), 1-20.

Cartwright, C. A. (1981). Effective programs for parents of young handicapped children. Topics in Early Childhood Special Education, 1(3), 1-9.

Cavallaro, C. C., Haney, M., \& Cabello, B. (1993). Developmentally appropriate strategies for promoting full participation in early childhood settings. Topics in Early Childhood Special Education, 13, 293-307.

Chiara, L., Schuster, J. W., Bell, J. K., \& Wolery, M. (1993). Comparison of small-group-massed-trial and individually-distributed-trial (embedded) instruction with preschoolers. Manuscript submitted for publication.

DeKlyen, M., \& Odom, S. L. (1989). Activity structure and social interactions with peers in developmentally integrated play groups. Journal of Early Intervention, 13, 342-352.

Dunst, C. J. (1985). Rethinking early intervention. Analysis and Intervention in Developmental Disabilities, 5, 165-201.

Dunst, C. J., Trivette, C., \& Deal, A. (1988). Enabling and empowering families: Principles and guidelines for practice. Cambridge, MA: Brookline Books. 
Dunst, C. J., Trivette, C. M., Starnes, A. L., Hamby, D. W., \& Gordon, N. J. (1993). Building and evaluating family support initiatives: A national study of programs for persons with developmental disabilities. Baltimore: Paul H. Brookes

Fewell, R. R., \& Oelwein, P. L. (1990). The relationship between time in integrated environments and developmental gains in young children with special needs. Topics in Early Childhood Special Education, 10(2), $104-116$.

Fleischer, K. H., Belgredan, J. H., Bagnato, S. J., \& Ogonosky, A. B. (1990). An overview of judgment-based assessment. Topics in Early Childhood Special Education, 10(3), 13-23.

Fleming, L. (1991). Using constant time delay during circle time. Doctoral dissertation, University of Kentucky, Lexington.

Fleming, L. A., Wolery, M., Weinzierl, C., Venn, M. L., \& Schroeder, C. (1991). Model for assessing and adapting teachers' roles in mainstreamed settings. Topics in Early Childhood Special Education, 11(1), 85-98.

Foster, M., Berger, M., \& McLean, M. (1981). Rethinking a good idea: A reassessment of parent involvement. Topics in Early Childhood Special Education, 1(3), 55-65.

Fox, L., \& Hanline, M. F. (1993). A preliminary evaluation of learning within developmentally appropriate early childhood settings. Topics in Early Childhood Special Education, 13, 308-327.

Garwood, S. G., \& Sheehan, R. (1989). Designing a comprehensive early intervention system: The challenge of PL 99-457. Austin, TX: Pro-Ed.

Guralnick, M. J. (1978). Early intervention and the integration of handicapped and nonhandicapped children. Baltimore: University Park Press.

Guralnick, M. J. (1981). The efficacy of integrating handicapped children in early education settings: Research implications. Topics in Early Childhood Special Education, 1(1), 57-71.

Hart, B., \& Risley, T. R. (1975). In vivo language training: Unanticipated and general effects. Journal of Applied Behavior Analysis, 8, 411-420.

Jacobson, J. M., Bushell, D., \& Risley, T. R. (1969). Switching requirements in a Head Start classroom. Journal of Applied Behavior Analysis, 2, $43-47$.

Johnson, J. E., \& Johnson, K. M. (1992). Clarifying the developmental perspective in response to Carta, Schwartz, Atwater, and McConnell. Topics in Early Childhood Special Education, 12, 439-457.

Johnson, K. M., \& Johnson, J. E. (1993). Rejoinder to Carta, Atwater, Schwartz, and McConnell. Topics in Early Childhood Special Education, 13, 255-257.

Kaiser, A. P., Yoder, P., \& Keetz, A. (1992). Evaluating milieu therapy. In S. F. Warren \& J. Reichle (Eds.), Causes and effects in communication and language intervention (pp. 9-47). Baltimore: Paul H. Brookes.

Kontos, S., \& File, N. (1993). Staff development in support of integration. In C. A. Peck, S. L. Odom, \& D. Bricker (Eds.), Integrating young children with disabilities into community programs: Ecological perspectives on research and implementation (pp. 169-186). Baltimore: Paul H. Brookes.

Kostelnik, M. J. (1992). Myths associated with developmentally appropriate programs. Young Children, 47, 17-23.

McEvoy, M. A., Nordquist, V. M., Twardosz, S., Heckman, K. A., Wehby, J. H., \& Denny, R. K. (1988). Promoting autistic children's peer interaction in an integrated early childhood setting using affection activities. Journal of Applied Behavior Analysis, 21, 193-200.

McLean, M. E., \& Odom, S. L. (1993). Practices for young children with and without disabilities: A comparison of DEC and NAEYC identified practices. Topics in Early Childhood Special Education, 13, 274-292.

McWilliam, R. A. (1991). Targeting teaching at children's use of time: Perspectives on preschoolers' engagement. Teaching Exceptional Children, 23(4), 42-43.

McWilliam, R. A. (in press). Survey of integrated therapy. Exceptional

\section{Children.}

McWilliam, R. A., \& Bailey, D. B. (1992). Promoting engagement and mastery. In D. B. Bailey \& M. Wolery (Eds.), Teaching infants and preschoolers with disabilities (2nd ed., pp. 229-255). Columbus, OH: Merrill.

National Association for the Education of Young Children and National Association of Early Childhood Specialists in State Departments of Education. (1991). Guidelines for appropriate curriculum content in programs serving children ages 3 through 8: A position statement. Young Children, 46, 21-38.

Neisworth, J. T., \& Bagnato, S. J. (1992). The case against intelligence testing in early intervention. Topics in Early Childhood Special Education, 12(1), 1-20.

Neisworth, J. T., \& Fewell, R. R. (1990). Foreword. Topics in Early Childhood Special Education, 10, ix-xi.

Norris, J. A. (1991). Providing developmentally appropriate intervention to infants and young children with handicaps. Topics in Early Childhood Special Education, 11(1), 21-35.

Novick, R. (in press). Activity-based intervention and developmentally appropriate practice. Topics in Early Childhood Special Education.

Odom, S. L., Hoyson, M., Jamieson, B., \& Strain, P. S. (1985). Increasing handicapped preschoolers' peer social interactions: Cross setting and component analysis. Journal of Applied Behavior Analysis, 18, 3-16.

Odom, S. L., McConnell, S. R., \& McEvoy, M. A. (1992). Social competence of young children with disabilities: Issues and strategies for intervention. Baltimore: Paul H. Brookes.

Odom, S. L., \& McEvoy, M. A. (1988). Integration of young children with handicaps and normally developing children. In S. L. Odom \& M. B. Karnes (Eds.), Early intervention for infants and children with handicaps: An empirical base (pp. 241-268). Baltimore: Paul H. Brookes.

Odom, S. L., \& McEvoy, M. A. (1990). Mainstreaming at the preschool level: Potential barriers and tasks for the field. Topics in Early Childhood Special Education, 10(2), 48-61.

Peck, C. A., Carlson, P., \& Helmstetter, E. (1992). Parent and teacher perceptions of outcomes for typically developing children enrolled in integrated early childhood programs: A statewide survey. Journal of Early Intervention, 16, 53-63.

Peck, C. A., \& Cooke, T. P. (1983). Benefits of mainstreaming at the early childhood level: How much can we expect? Analysis \& Intervention in Developmental Disabilities, 3, 1-22.

Peck, C. A., Odom, S. L., \& Bricker, D. (1993). Integrating young children with disabilities into community programs: Ecological perspectives on research and implementation. Baltimore: Paul H. Brookes.

Pugach, M. C., \& Johnson, L. J. (1990). Meeting diverse needs through professional peer consultation. In W. Stainback \& S. Stainback (Eds.), Support networks for inclusive schooling: Interdependent integrated education (pp. 123-137). Baltimore: Paul H. Brookes.

Rettig, M., Kallam, M., \& McCarthy-Salm, K. (1993). The effect of social and isolate toys on social interactions of preschool-aged children. Education \& Training in Mental Retardation, 28, 252-256.

Rowbury, T. G., Baer, A. M., \& Baer, D. M. (1976). Interactions between teacher guidance and contingent access to play in developing preacademic skills of deviant preschool children. Journal of Applied Behavior Analysis, 9, 85-104.

Rule, S., Stowitschek, J. J., Innocenti, M., Striefel, S., Killoran, J., Swezey, K., \& Boswell, C. (1987). The social integration program: An analysis of the effects of mainstreaming handicapped children into day care centers. Education \& Treatment of Children, 10, 175-192.

Smith, B. J., \& Rose, D. F. (1993). Administrator's policy handbook for preschool mainstreaming. Cambridge, MA: Brookline Books. 


\section{Guidelines for Adjusting Activities to Teach Young Children with Disabilities}

Embed instructional opportunities into existing activities and routines.

To teach peer imitation to young children with autism, five progressive time-delay trials were dispersed throughout daily art activities. The trials were not implemented one after another, but were implemented when the peer was doing a unique behavior that could be imitated and when it did not interfere with the child's ongoing behavior. All children learned to imitate their peer's behavior (Venn, Wolery, Werts, et al., 1993).

To teach picture naming to young children with and without developmental delays, constant time delay was interspersed throughout the day in a variety of activities. The trials were implemented so as not to interfere with children's ongoing behavior. At least 15 minutes occurred between trials. All children learned to name the pictures (Chiara, Schuster, Bell, \& Wolery, 1993).

Adjust activities by changing what children do in them.

To increase children's social interactions during free play periods, the nature of what children did during group activities was adjusted. Specifically, group affection activities (games and songs that increased physical contact and interaction) were used. This resulted in increased social contact during free play (McEvoy et al., 1988).

To teach various preacademic skills, teachers dispersed single, brief instructional trials at the beginning of in-class transitions. The children quickly acquired the targeted skills (Werts, Wolery, Holcombe-Ligon, Vassilaros, \& Billings, 1992; Wolery, Doyle, Gast, Ault, \& Simpson, 1993).

Adjust activities/routines by adapting the materials and their access.

To increase the amount of social play during free play periods, teachers provided toys that were more likely to promote social interactions. Providing these toys resulted in increased social contact (Rettig, Kallam, \& McCarthy-Salm, 1993).

To increase opportunities for children to initiate communicative exchanges and thereby have opportunities to practice and learn more elaborate communicative behaviors, teachers placed some toys on a "must-ask shelf." To gain access to these toys, children were required to ask an adult for them. The teachers then used incidental teaching and saw increases in children's communicative behaviors (Hart \& Risley, 1975).

Adjust activities/routines by providing additional opportunities to respond.

To teach preacademic behaviors, individualized constant timedelay trials were interspersed with other circle-time activi- ties. Children with developmental delays acquired the targeted skills (Fleming, 1991).

Use shorter but more frequent activities to increase opportunities for instruction.

To teach self-feeding, more meals were provided each day and the amount of food provided at each meal was decreased. Teacher prompting with graduated guidance in this arrangement resulted in rapid increases in children's selffeeding behaviors (Azrin \& Armstrong, 1973).

Adjust activities by changing the rules of access to particular areas.

To increase children's contact with a classroom area they avoided and to decrease the number of area switches, children were required to go to the area they avoided each time they wanted to switch areas. This resulted in increased engagement in the avoided area and reduced the number of task switches (Jacobson, Bushell, \& Risley, 1969; Rowbury, Baer, \& Baer, 1976).

Adjust activities by changing the social composition or rules of social activities.

To increase the amount of social contact between children, structured play activities with defined roles and routines were used. This resulted in more social initiations and responses to children with disabilities (DeKlyen \& Odom, 1989).

To increase the number and rate of turn-taking in conversational exchanges, a highly loquacious child was seated next to a child with speech and language impairment during snack and meals. This physical proximity resulted in increased turn-taking (Wolery, Anthony, Heckathorn, Filla, \& Bell, 1993).

Adjust activities by training peers to engage in facilitative behavior.

To promote requesting behaviors in children with severe disabilities, their peers without disabilities were taught to use the mand-model procedure. The peers were taught to use the procedure in separate sessions, but implemented it during snack activities (Venn, Wolery, Fleming, et al., 1993).

To increase the amount of social interactions between children with and without disabilities, typically developing peers were taught to initiate social exchanges with their peers. This resulted in increased social interactions between children (Odom, Hoyson, Jamieson, \& Strain, 1985). 
Stayton, V. D., \& Miller, P. S. (1993). Combining general and special early childhood education standards in personnel preparation programs: Experiences from two states. Topics in Early Childhood Special Education, 13, 372-387.

Stoneman, Z. (1993). The effects of attitude on preschool integration. In C. A. Peck, S. L. Odom, \& D. Bricker (Eds.), Integrating young children with disabilities into community programs: Ecological perspectives on research and implementation (pp. 223-248). Baltimore: Paul H. Brookes.

Taylor, S. J. (1988). Caught in the continuum: A critical analysis of the principle of the least restrictive environment. The Journal of the Association for Persons with Severe Handicaps, 13, 41-53.

Templeman, T. P., Fredericks, H. D., \& Udell, T. (1989). Integration of children with moderate and severe handicaps into a day care center. Journal of Early Intervention, 13, 315-328.

Turnbull, H. R. (1990). Free appropriate public education: The law and children with disabilities (3rd ed.). Denver: Love.

U. S. Department of Education. (1993). To assure the free appropriate public education of all children with disabilities: Fifteenth Annual Report to Congress on the Implementation of the Individuals with Disabilities Education Act. Washington, DC: U. S. Department of Education.

Venn, M. L., \& Wolery, M. (1991). Structural analysis of preschool classroom activities. Unpublished observational code, Allegheny-Singer Research Institute, Pittsburgh, PA.

Venn, M. L., Wolery, M., Fleming, L. A., DeCesare, L. D., Morris, A., \& Sigesmund, M. H. (1993). Effects of teaching preschool peers to use the mand-model procedure during snack activities. American Journal of Speech-Language Pathology, 2(1), 38-46.

Venn, M. L., Wolery, M., Werts, M. G., Morris, A., DeCesare, L. D., \& Cuffs, M. S. (1993). Embedding instruction in art activities to teach preschoolers with disabilities to imitate their peers. Early Childhood Research Quarterly, 8, 277-294.

Werts, M. G., Wolery, M., Holcombe-Ligon, A., Vassilaros, M. A., \& Billings, S. S. (1992). Efficacy of transition-based teaching with instructive feedback. Education \& Treatment of Children, 15, 320-334.

Wolery, M. (1989). Using assessment information to plan instructional programs. In D. B. Bailey \& M. Wolery (Eds.), Assessing infants and preschoolers with handicaps (pp. 478-495). Columbus, OH: Merrill.

Wolery, M., Anthony, L., Heckathorn, K., Filla, A., \& Bell, R. (1993). Promoting preschoolers conversations at snack and mealtimes. Manuscript in preparation.

Wolery, M., Ault, M. J., \& Doyle, P. M. (1992). Teaching students with moderate and severe disabilities: Use of response prompting strategies. White Plains, NY: Longman.

Wolery, M., \& Bredekamp, S. (in press). Developmentally appropriate practice and young children with special needs: Contextual issues and a framework for convergence. Journal of Early Intervention.

Wolery, M., Doyle, P. M., Gast, D. L., Ault, M. J., \& Simpson, S. L. (1993). Comparison of progressive time delay and transition-based teaching with preschoolers who have developmental delays. Journal of Early Intervention, 17, 160-176.

Wolery, M., Holcombe, A., Brookfield, J., Huffman, K., Schroeder, C., Martin, C. G., Venn, M. L., Werts, M. G., \& Fleming, L. A. (1993). The extent and nature of preschool mainstreaming: A survey of general early educators. Journal of Special Education, 27, 222-234.

Wolery, M., Huffman, K., Brookfield, J., Schroeder, C., Venn, M. L., Holcombe, A., Fleming, L. A., \& Martin, C. G. (in press). Benefits and barriers to preschool mainstreaming: Perceptions of general early childhood educators. Exceptional Children.

Wolery, M., Huffman, K., Holcombe, A., Martin, C. G., Brookfield, J., Schroeder, C., \& Venn, M. L. (in press). Preschool mainstreaming: Perceptions of barriers and benefits by faculty in general early childhood education. Teacher Education \& Special Education.

Wolery, M., Martin, C. G., Schroeder, C., Huffman, K., Venn, M. L., Holcombe, A., Brookfield, J., \& Fleming, L. A. (in press). Employment of educators in preschool mainstreaming: A survey of general early educators. Journal of Early Intervention.

Wolery, M., Strain, P. S., \& Bailey, D. B. (1992). Reaching the potentials of children with special needs. In S. Bredekamp \& T. Rosegrant (Ed.), Reaching potentials: Appropriate curriculum and assessment for young children (pp. 92-111). Washington, DC: National Association for the Education of Young Children.

Wolery, M., Venn, M. L., Holcombe, A., Brookfield, J., Martin, C. G., Huffman, K., Schroeder, C., \& Fleming, L. A. (in press). Availability of related services in preschool programs: A survey of general early educators. Exceptional Children.

Wolery, M., Venn, M. L., Schroeder, C., Holcombe, A., Huffman, K., Martin, C. G., Brookfield, J., \& Fleming, L. A. (in press). A survey of the extent to which speech-language pathologists are employed in preschool programs. Language, Speech, \& Hearing Services in the Schools.

Wolery, M., Werts, M. G., Snyder, E., \& Caldwell, N. (1993). Extent and nature of inclusion in elementary schools throughout the nation. Manuscript in preparation.

Wolery, M., \& Wilbers, J. S. (in press). Including children with special needs in preschool programs: Research and implications for practice. Washington, DC: NAEYC.

Preparation of this report was supported by the U. S. Department of Education, Office of Special Education and Rehabilitative Services, Early Education Program for Children with Disabilities (Research Institute on Preschool Mainstreaming, Grant No. H024K90005). The opinions expressed, however, do not necessarily reflect the policy of the U. S. Department of Education, and no official endorsement should be inferred.

\section{PERMISSIONS AND COPYRIGHT}

All rights are reserved. No part of this publication may be reproduced, photocopied, faxed, stored in a retrieval system, or transmitted, in any form or by any means, electronic, mechanical, recording or otherwise, without the prior written permission of the publisher.
Back issues are available for sale. Reproduction requires permission and payment of fees. It is illegal and a violation of federal copyright law to reproduce this publication without permission. Direct all inquiries to the permissions editor. 